many students are seriously handicapped in their work by remediable faults in their modes of reading. Within a day or two of the publication of this bibliography appeared No. 1 of vol. 24 of the University of Colorado Studies containing abstracts of 136 theses for higher degrees. An analysis of the subject headings of the theses affords further evidence of what might almost be called the rage for educational research prevalent in some American universities, for no fewer than 47 of the theses are devoted to research in this field.

\section{Records of Bushman Art}

The Department of the Interior of the Union of South Africa and the Commission for the Preservation. of the Natural and Historical Monuments, Relics and Antiquities of South Africa have issued an official circular inviting the co-operation and assistance of members of the public in recording and preserving examples of Bushman rock-painting and drawing. In asking observers to forward such records to Prof. C. van Riet Lowe, as director of the Bureau of Archæology at Johannesburg, the circular points out that although the existence of a large number of such examples of Bushman art is already known, it is certain that the list is by no means complete, while time, exposure to weather, as well as acts of vandalism are obliterating many of them year by year. In order that the records may be as complete as possible, the circular enumerates the data which are essential for the purpose of accurate record, as well as for archæological study, and gives instructions on the best methods of taking photographs and squeezes in varying conditions. The circular, as received, is accompanied by an excellent and extremely instructive map, showing the distribution of the known sites on which examples of the paintings and engravings have been recorded, as well as sites which have been proclaimed for preservation by the Commission for the Preservation of Natural and Historic Monu- . ments.

\section{Fire Precautions in Electrical Stations}

SERIOUs fires from electrical plant in power stations are fortunately rare in Great Britain, but during the last few years there have been several disastrous fires both at home and abroad, and so the paper on fire precautions by F. C. Winfield read to the Institution of Electrical Engineers on February 11 is a useful one. In electrical supply it is recognized that the maintenance of this supply is the outstanding requirement. This is usually done by duplicating all the principal cables supplying the current, and also some of the plant. Since all electrical plant is subject to the two risks of fire and explosion, this provision does not secure the desired maintenance of the supply unless measures are taken to ensure that such duplicates cannot be simultaneously impaired. It is necessary therefore to provide physical separation of electrical duplicates by dividing them up in separate buildings or enclosures. Brick walls and reinforced concrete construction have excellent fireresisting properties. Pitched roofs supported by steel trusses should be protected by a fire-resisting inner ceiling. All windows should be of wired glass and all internal doors of fireproof self-closing design. The development of the oil-less circuit and breaker on the Continent is a step in the right direction. An important factor in fighting an oil fire is the dense black smoke, which impedes or prohibits access to the seat of the fire. This is a very serious consideration in dealing with fires which occur in the inner regions of large power stations. For this reason it is recommended that all large transformers or heavy switch-gear should be mounted in separate buildings or in chambers opening to the outer air and sealed off from the inner side. Unfortunately, no practical method of routine testing has yet been devised by means of which the failures that produce fires can be anticipated.

\section{Underwater Power and Telephone Cables}

In the course of developing underground cable networks, the engineer has sometimes to negotiate waterways and harbours. For large waterways three methods are used. The first is to make a special cable tunnel. But the expense of construction is heavy, and is only justified when a large block of main cables has to be taken across. Examples of this type are the crossings under the Thames at Barking, Deptford and Battersea and underneath the Tyne at Newcastle. The second method is to dredge a trench in the river bed in which the cables are laid directly, and the third method is to lay them in the bed of the waterway without recourse to dredging. The second method is, when practicable, preferable to the third method, especially in navigable waterways, where the ships' anchors damage them. In certain cases, owing to the width of the waterway or because the nature of its bed renders dredging impracticable, the third method is employed. In the Engineering Supplement to the Siemens Magazine of March, it is pointed out that when this is done in running or tidal waters, a new problem arises. No matter how carefully the cable is laid, it may at any time, due to the shifting of the bottom, be left suspended between two points. In this condition, it is subject to high-frequency vibrations set up by the current. These vibrations are very harmful to the lead as they rapidly produce inter-crystalline fracture and failure due to ingress of water. Messrs. Siemens have successfully combated this trouble by a special type of cable. A rubber hose protection is applied between the lead sheathing and the armouring. This damps out harmful frequency vibrations before they reach the lead.

\section{Progress in Marine Radio Communication}

THE first practical application of radio provided communication with ships at sea over distances and under conditions which made all other forms of communication impossible. More than thirty-five years have elapsed since that first application, and marine radio still remains unique for this particular purpose, so important to commerce and so essential to safety. In no other field, except that of air trans- 